\title{
CELLO AS A LANGUAGE TEACHING METHOD IN INDUSTRIAL REVOLUTION 4.0 ERA
}

\author{
Halimah \\ Applied Linguistics Study, Postgraduate Program, University State of Jakarta, Indonesia \\ Department of English Education, Faculty of Teacher Training and Education, University of \\ Suryakancana, Indonesia \\ E-mail: halimah_lt15s3@mahasiswa.unj.ac.id; halimah@unsur.ac.id
}

Gufran Ali Ibrahim

National Agency for Language Development and Cultivation, Jakarta, Indonesia

E-mail:ibrahim.kakalu@gmail.com

Ninuk Lustyantie

Applied Linguistics, Postgraduate Program, University State of Jakarta, Indonesia

E-mail: ninuk.lustyantie@unj.ac.id

\begin{abstract}
APA Citation: Halimah, H., Ibrahim, G. A., \& Lustyantie, N. (2018). CELLO as a language teaching method in industrial revolution 4.0 era. English Review: Journal of English Education, 7(1), 75-82. doi: 10.25134/erjee.v7i1.1497.
\end{abstract}

Received: 08-08-2018

Accepted: 19-10-2018

Published: 01-12-2018

\begin{abstract}
CELLO is derived from Community English Language Learning and Orai. It is a new teaching method developed especially in the community of English language learning based on the idea of Curran's work on teaching method. CELLO is a combination between an innovative teaching method and media technology called Orai Application that is applied in teaching and learning of speaking especially in fostering students' fluency. Today, all graduates face a world transformed by technology, in which the Internet, cloud computing, and social media create different opportunities and challenges for formal education systems. This paper aims to explore the use of CELLO in assisting student's speaking fluency. This classroom action research consists of three cycles in which each cycle consists of six stages, namely identify the problem, data gathering, data interpreting, action on evidence, evaluation, and revision. The obtained data showed that CELLO method could improve students' speaking fluency. Based on the finding, implementing CELLO method is strongly recommended in teaching speaking especially at fostering students' speaking fluency.
\end{abstract}

Keywords: CELLO; speaking fluency; technology 4.0; industrial revolution; action research.

\section{INTRODUCTION}

In the era of globalization and industrial revolution 4.0 in which it is powered by artificial intelligence and it will transform the workplace from task-based characteristics to the human centered characteristics, an ability to speak English in this era is very important to be mastered as a medium of communication between nations and people from various backgrounds. In this era, the ability to speak a second language fluently has become necessary, especially for those who want to advance in certain field of human endeavor. Fluency in speaking is known as the natural ability to speak spontaneously, quickly and comprehensibly with few numbers of errors that may distract the listener from the speaker's message. Accuracy and fluency are the two factors which determine the success of English language students in the future.

The key to successful communication is to be able to speak effectively and articulately which is linked to one's success in life as it occupies an important position both individually and socially (Amiri, Jahedi, \& Othman, 2017). 
However, English speaking is not an easy thing. Leong and Ahmadi (2017) say that English speakers should understand important components of speech such as pronunciation, grammar, vocabulary, fluency, and comprehension. Therefore, problems often arise in learning to speak English. With its complex grammar and morphological systems, stress and intonation patterns, and pronunciation difficulty, many people struggle in achieving fluency.

Nevertheless, experience shows that with constant exposure and practice, developing fluency in a second language is made possible even with the most difficult languages. Individuals who spend time in the country of the target language come back with improved pronunciation and understanding of the mechanics of the language. On the other hand, when individuals do not have constant access to native speakers and practice opportunities, achieving or maintaining fluency becomes problematic.

Several studies have found problems arising in learning to speak. First, Leong and Ahmadi (2017) found that students were unable to communicate fluently and accurately due to lack of knowledge about the topic being discussed. Fluent refers to the speaking speed and smoothness of the language delivery (Srivastava, 2014; Hadijah, 2014). Meanwhile, fluency refers to a level of proficiency in communication. It is the ability to produce spoken sentences with ease, efficiency, without pauses or a breakdown of communication (Yang, 2014). The existence of fillers such as uh, um, well, you know, I mean, like are among the common ones used in spoken language indicating influent (Al-khasawneh \& Huwari, 2014).

Based on a number of findings, it can be concluded that there are two indicators effecting students' speaking fluency, namely; 1) Too many hesitations and pauses in speaking may obstruct the speaking fluency and also depress the speaker (Wang, 2014); and 2) Repeating words or phrases during speaking.
Nowadays, people are standing on the edge of a technological revolution that is called industry revolution 4.0 in which having proficiency to speak in English especially for university students is quite important in order to be able to build a connection with others around the world through the communication.

As today's learners belong to the Digital Age, teachers also must adapt to use technology and multi-media based learning resources to impart the functional teaching of English (Daniel, 2014).

There are numerous of researchers conducted research on the issues of the use of media technology in language teaching and learning, such as Bahadorfar and Omidvar (2014) who proposed some technologies that can be applied in language teaching, namely Communication lab Speech recognition software, Internet, TELL (Technology Enhanced Language Learning), Pod casting, Quick Link Pen, and Quicktionary. They said that technology gives learners a chance to engage in selfdirected actions, opportunities for self-paced interactions, privacy, and a safe environment in which errors get corrected and specific feedback is given. Feedback by a machine offers additional value by its ability to track mistakes and link the student immediately to exercises that focus on specific errors.

Godwin-jones (2009) stated that there are a number of tools for speech analysis, many of which can be and have been adapted for language learning. KayPentax (formerly Kay Elemetrics) markets the widely used Visi-Pitch, now at version four. The latest release features a waveform editor, auditory feedback and voice games. The games are quite basic, for example, an animated graphic based on pitch and amplitude of the sound input. The company also sells the popular Computerized Speech Lab (CSL), a powerful hardware/software speech analysis system. Its hardware is used in conjunction with a PC and offers highquality input and output as well as a variety of software add-ons. The latter includes a Video Phonetics Program, which features a 
ENGLISH REVIEW: Journal of English Education Volume 7, Issue 1, December 2018

synchronized display of video and acoustic data. The most widely used option with CSL is Real-Time Pitch, which provides extensive analysis capabilities to compare two speech samples. KayPentax also sells Multi-Speech, a software only speech analysis program, with similar software options to CSL. The EduSpeak speech recognition system from SRI International supports 9 languages and includes program interfaces for use in Macromedia Director and Microsoft ActiveX.

For oral language testing, the Versant suite of tests (available for English, Spanish and Arabic) incorporate speech processing and can be taken over the phone or on a computer. A free on-line demo for English illustrates how the 15-minute test works. The Speech Analyzer from SIL International (formerly the Summer Institute of Linguistics) performs frequency and spectral analysis and can be used to annotate phonetic transcriptions. Of particular interest to language learning, it also allows for slowed playback and looping of audio. SIL International makes available other tools for language analysis and recording including Phonology Assistant and WinCECIL, both of which can be used together with Speech Analyzer. A widely used authoring tool is WinPitch LTL, a Windows desktop application. Teachers create lessons consisting of a sequence of speech models, to be repeated or imitated by the learner, with the model speech displayed in graphic form on the left and the learner's input on the right. The program features Unicode word processing and Web linking. As with similar tools, WinPitch LTL offers powerful capabilities but it is likely the rare language teacher who can find the time to create pronunciation lessons themselves from scratch. Teachers who do, like Marjorie Chan for teaching Chinese (2003), find that the flexibility and customizability of such tools, as well, of course, as evidence of student improvement, compensate for the time and effort involved.

Those researchers used media technology in language teaching. Yet, over
p-ISSN 2301-7554, e-ISSN 2541-3643

https://journal.uniku.ac.id/index.php/ERJEE

those researches, the use of Orai application in teaching and learning speaking has not ever been revealed by the researchers. CELLO method promotes the studentcentered learning process and decreased the teacher-centered learning. Through the stages of the learning process, the teacher's role is as a facilitator and a counselor.

There are some activities that can be done using CELLO method in speaking class. First is recording. In this activity, the students record their speech. Second, listen. The students listen to their recorded speech. Third is correct. The students' activity is corrected for the error in language occurred on their speech. The fourth activity is repeating the recorder in which the students repeat and record their correct speech.

Orai is one of the most popular Android mobile Application (Bodana, 2017). It is an application to help people to be better speaker. It is developed by Danish Dhamani. Orai gives people the confidence and skills to speak powerfully when on stage, in front of a room, or in everyday life (Chang, 2017). It serves as people speech coach (Takahashi, 2017). Orai is powered by artificial intelligence which gives immediate, personalized feedback on users' public speaking prowess (Douglas, 2017). Orai helps people in preparing a better speaker (Olivia, 2018).

To use the app, learners must download it for smartphones (Figure 1). It is compatible for almost all iOS and Android mobile devices (Bodana, 2017).

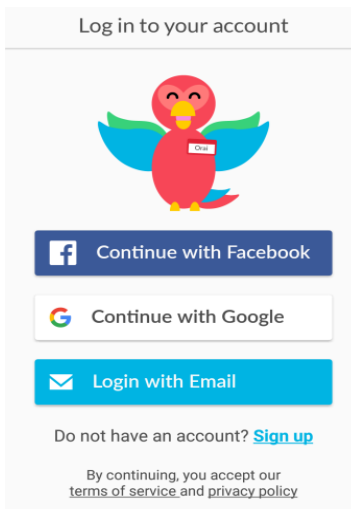

Figure 1. Orai application figure 
There are some features in Orai Application, namely; 1) it gives instant feedback. Orai gives feedback on students' use of filler words, pacing, energy level, pauses, and clarity - all in seconds (Figure 2); 2) learn through Lessons (Figure 3). Orai worked with over 100 speaking coaches to create fun, interactive lessons to improve the students' speaking skills (Figure 4); and 3) Students can practice anytime (Figure 5).

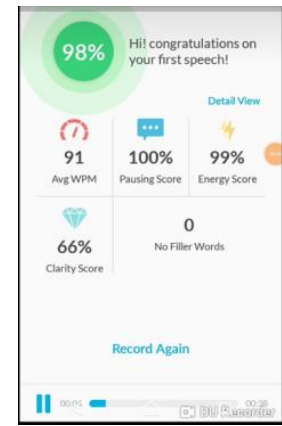

Figure 2. Instant feedback from Orai App

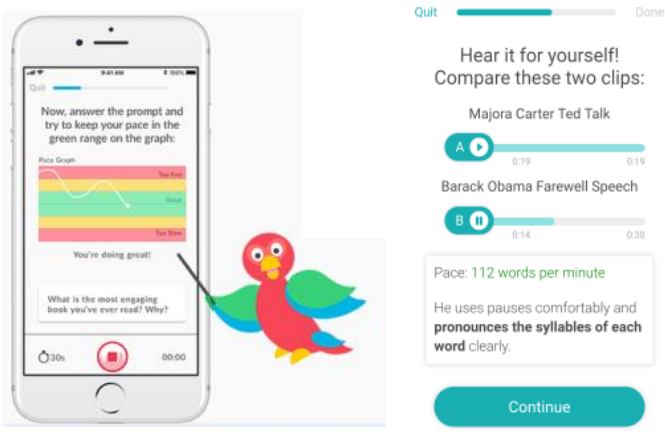

Figure 3. Lessons available in Orai App

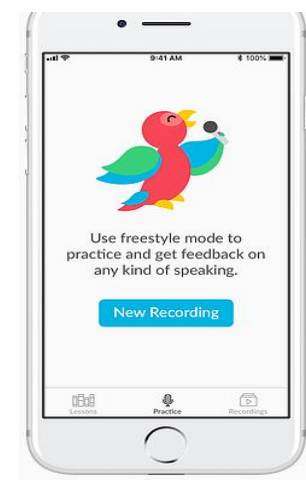

Figure 4. Students can practice anytime

Through the Artificial Intelligent, as the learners have done recording, this app offers an interesting solution to a common problem (Bodana, 2017). Orai picks up on filler words like um. For instance, the record app tracks the number of "ums" that is uttered and points them out to speaker as unnecessary filler words that are signs of hesitation (Chang, 2017), see Figure 5. It tells speaker if she/he is speaking too fast or too slow and provides his/her a transcript of what speaker just said (Figure 8) - which highlights speaker's varying energy or lack thereof (Figure 6).

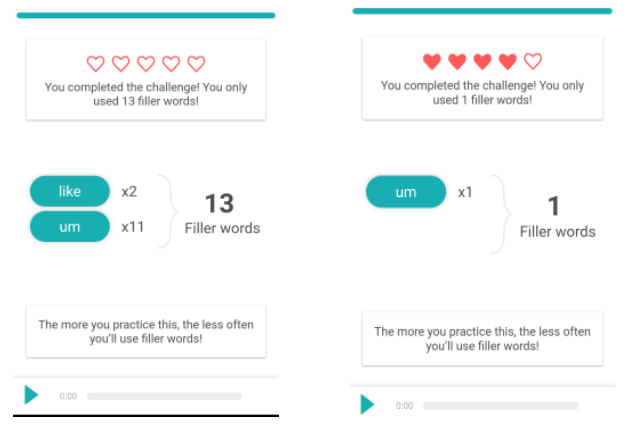

Figure 5. Orai detect filler use

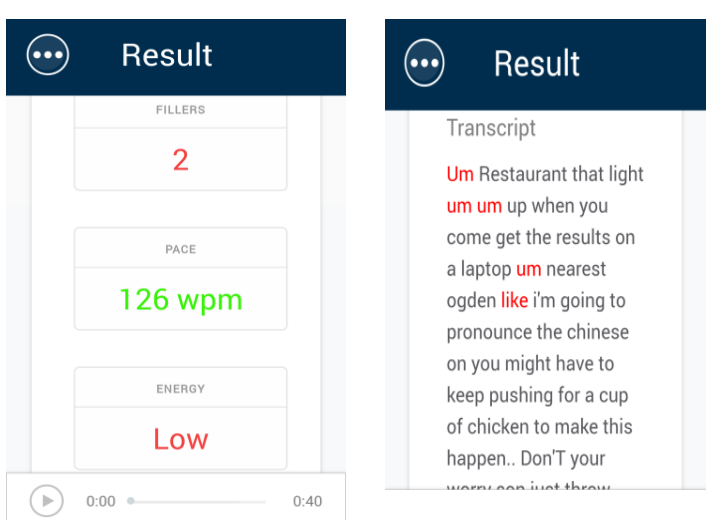

Figure 6. Analytic result of Orai App

It also tells the speaker how clearly speaker is enunciating words and counts the number of words that speaker says in a minute as well as monitoring the pace of her/his speech. Besides, Orai measures the "energy" of speaker speech, like whether she/he speaks in a monotone that will put people to sleep or whether she/he emphasizes certain words. Orai really helps learner to prepare speaking fluency and confidently.

Accordingly, this article reports the results of the research dealing with the application of the orchestrating Orai application into CLL method by answering the following research question: How does CELLO method application improve students' fluency in speaking practice? 
ENGLISH REVIEW: Journal of English Education Volume 7, Issue 1, December 2018

\section{METHOD}

The type of the research conducted in this study was collaborated action research. It is a type of action research characterized by the focus on single class or several classes with common issues and the presence of substitute teachers. The subjects were 27 University second semester students studying at English Education Department in a Private University in Cianjur.

The data of this study were collected through test and observation on the process of teaching and learning using Orai and CLL method. The tool used was video recorder. The data obtained in this research were qualitative and quantitative data. The data were then analyzed using descriptive statistics and constant comparative method. To know the improvement of students' fluency, the researcher compared the mean score of post-test 1 , post-test 2 , as well as post-test 3 in order to know the effectiveness of implementing Orai Application in CLL method to teach speaking fluency.

\section{RESULTS AND DISCUSSION}

Statistically, the result of students' tests is presented in the following graphic.

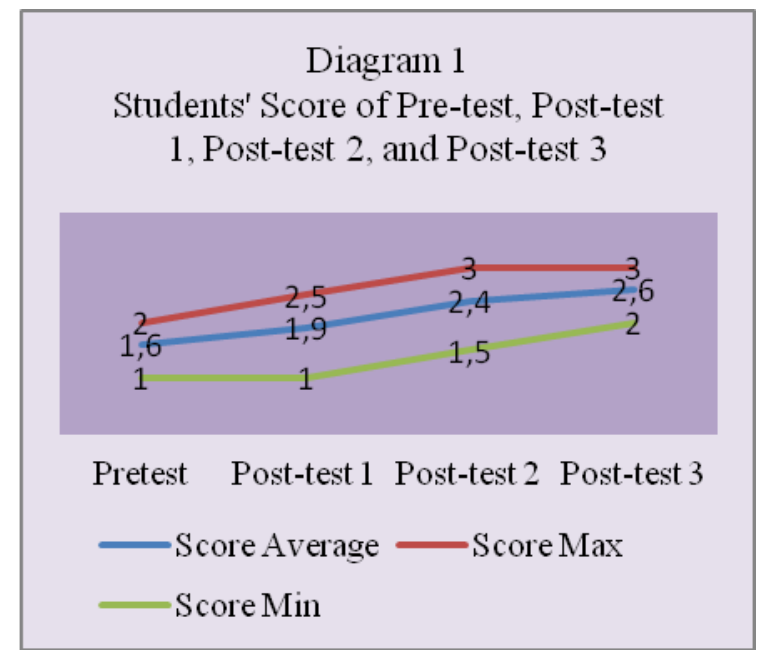

Graph 1. Students'score

This graphic clearly indicates that there is improvement of the students from cycle to cycle. The minimum score was constant in pre-test and in post-test 1. However, it increased to 1.5 in post-test 2 , and increased
p-ISSN 2301-7554, e-ISSN 2541-3643

https://journal.uniku.ac.id/index.php/ERJEE

again to 2 in post-test 3 . The maximal score was 2 in the pre-test. It increased to 2.5 in post-test 1,3 in post-test 2 , and it was constant in this score in post-test 3 . The improvement also happened on students' average score. It was 1.6 in pre-test and increased to 1.9 in post-test $1,2.4$ in posttest 2 , and became 2.6 in post-test 3 .

It can be reported that the increasing of students' speaking fluency score above deals with the score speech rate, articulation, phonation time ratio, and also the total number of pause fillers per minute. Here, the students were able to manipulate the time spent for speaking in order to reduce the frequency of silent, pause filler, and also hesitancy that are usually occurred in speaking. The students are also able to produce more units of syllable. By using Orai application, the students had the opportunities to make some repetition of their speech.

Another improvement also happened on the students' attitude toward learning process. From the observation, the writer found a new formula in using CELLO method in teaching speaking. This formula consists of four stages, namely record, listen, correct, and repeat. Finally, the writer called this formula as RLCR. The stages of the activities are described as follows.

The first stage of students' activity was recording. In this stage, the students recorded their utterances or speaking. Hence, before recording their voice, the students were allowed to ask the teacher about what they were going to utter in L1, then the teacher translated the utterances into the target language. The students uttered the utterance modeled by the teacher. The students then practiced in uttering the utterance many times. The purpose of this activity is to get the students' fluency. It was supported by Muhammad (2017) who said that repetition can help students' fluency. After they were sure about their pronunciation, their intonation, and they were confident enough to record their utterances, then they recorded their 
speaking. Only the target language was recorded by using Orai application.

The second stage was listening. After the students recorded their speeches the device would take a few second to analyze students' speech. The device then showed the result and gave direct feedback to the students. The feedback covered pronunciation, tone, energy, filler as well as the clarity of the students' speech as well as the score of the speech. The result of the analysis of pronunciation can be seen in the transcribe sheet. When there was a blank sheet, it means that the students produced incorrect pronunciation. The students' result of speaking energy was indicated by the graphic of energy. There were two colors in it; yellow color indicated that students' speaking was monotonous and purple color indicated the students' speaking energy. The students' unnecessary filler was also analyzed. At the end, the students were able to get their scores of clarity. The students also got suggestion from the device. Based on the suggestions, the students then listened to their recording speech. In this stage, the students would highlight their mistakes.

Having reading the result or the analysis, the students might make some corrections dealing with the mispronunciation, the tone, the filler, or the energy suggested by the device. In this stage, they discussed with their fellow or consulted to the teacher. By having discussion, it means that they have chance to communicate with their friend and the teacher to build a relationship between students-students and student-teacher. In this stage, the students practiced reading the correct speech.

The final stage was repeating. Once the students corrected their speech, they might do some repetitions in practicing the speech through the recording. As the score increased and they felt comfort with the score, they might submit the score to the teacher together with the transcription of the text.

As the research revealed, being afraid of speaking in front of other is common for the students even for English department students. English teacher should be able to find a better solution to help students to cover their fear of speaking. One of the things than can be done is by applying an appropriate teaching method which not only makes the students active and creative in the teaching and learning process, but also it should pay attention on the students' psychology. The teacher also should be creative in using a media in applying the teaching method in order to create a joyful teaching and learning process.

Community Language Learning (CLL) method is an innovative teaching method that pays attention on the students' feeling, desire, and opinion during the process of teaching and learning. In the application, this method is assisted by a tape recorder. As this device is stay no longer in this era, it is substituted by an application of mobile technology called Orai that can be downloaded from Google play store to Smartphone. Then, this application and CLL method are orchestrated to be applied in speaking class in order to help students to be better in speaking skill. It is supported by Bahadorfar and Omidvar (2014) who noted that technological tools have been regarded as ways of helping students improve language skills, such as speaking skill.

Orai application can help students in increasing their speaking and all aspects of speaking. For instance, the app tracks the number of "ums" that the students utter and point them out to the students as unnecessary filler words that are sign hesitation. As the students are able to manage the use of filler during the speaking, it shows that they can speak fluently.

In addition, Orai also helps students to fix their pronunciation, intonation as well as their speed of speaking (Douglas, 2017). The app uses artificial intelligence (AI), developed by Gupta, to track users' speech and give instantaneous, personalized feedback based on three indicators: use of filler words like "um" and "er", speed of speech (130-150 words per minute is the optimum), and energy or variation in tone.

Orai application can be used to practice speaking in the class and out of the class. It 
ENGLISH REVIEW: Journal of English Education Volume 7, Issue 1, December 2018

promotes students' self-study. Moreover, the students suggest that Orai application should be applied in other language subject, such as in phonology and reading class. It is in line with statement that the participants' digital mindsets, comprising assumptions about affordances of digital technologies, shaped the ways in which the participants used digital technologies within and beyond classrooms.

Research has revealed that second language learners often seem passive and reticent in language classrooms. In the age of globalization, however, there is an urgent need for English as a Foreign Language (EFL) teachers to enhance their reticent students' confidence to help them take part more actively in classroom oral activities (Doqaruni, 2014).

CELLO method is an innovative new teaching method especially for English community learning. It becomes a more effective teaching method assisted by a smart app called Orai. The effectiveness of this method could be seen from the stages done by the students in learning speaking in which it promotes the students to learn independently and in joyful environment. Orai is a very smart app. For example, if in a uttering the utterances the students too monotonous, the app will give a direct feedback. Another interesting characteristic of the app is the Playback button that learners can listen to the speech being spoken in the recorder. Through this feature, Orai offers personalized exercises for each learner, focusing on their weaknesses and improving their skills.

Despite these good features in Orai, there are a few cautionary notes. First, Orai's voice recognition software did not always get it right. In fact, many of the words in students' transcripts were incorrect or replaced with an underscore, symbolizing that the software did not understand. This made the students frustration. This seemed to skew other areas of feedback as well, such as counting the number of filler words used. In addition, the app would give users more incentive to use it if it provided cumulative
p-ISSN 2301-7554, e-ISSN 2541-3643

https://journal.uniku.ac.id/index.php/ERJEE

feedback over time. For instance, if it kept track of the number of filler words a speaker used over the course of several months, their pace, or energy levels, users would be able to track their long-term progress in specific areas.

It must be noted that Orai does not provide any grammatical explanations. It only immerses the learner in the target language by offering exercises centered on new vocabulary. To learn the grammar, learners must deduce the principles of grammar on their own and through trial and error. Even though Orai penalizes the learners for the tiniest of mistakes and points out the most insignificant phase of speech, it does not present the learners with any grammar notes or rules of any kind. Yet, in the term of fluency, this app gives some suggestions what the students should do to fix their speech. It also gives the results of unnecessary filler during speaking. Through this way, the students will be aware of the use of filler when they speak.

\section{CONCLUSION}

This study was carried out to describe how mobile technology device called Orai application was orchestrated into a language teaching method named CLL to be used in teaching speaking that helps the students to become better speaker and to report students' perception on the use of Orai application in speaking course. To grab the outcome of teaching and learning effectively, an appropriate teaching method should be considered by the teacher. Supporting media in teaching and learning is extremely needed in order to assist student in learning in learning practice.

CLL method is an appropriate teaching method to be applied in language teaching and learning especially in speaking class. This method sees the students' as a whole person who has feeling, desire, love, and the desire of sense of belonging. This method suggested the teacher to pay attention of student's physiological factors. The old recorder equipment used in this method was a tape recorder. Hence, this device did no 
longer exist. Therefore the writer substituted this device with an application available in a mobile technology called Orai, then combining it into CLL method in teaching speaking. Many researchers reported that CLL method was able to reduce the students' fear to speak. It forced the students-centered learning and reduced teacher- centered study.

Orai application is a unique and excellent app to be used as a supporting media for speaking course. It provokes the students to learn actively and happily in the classroom. They do not to be worry of making mistake during speaking practice since the app gives them feedback directly and gives suggestion what should they do.

Orchestrating CLL method and Orai application is strongly recommended for both the teacher and students in order to help them to be better speaker.

\section{REFERENCES}

Al-khasawneh, F. M., \& Huwari, I. F. (2014). The interference of mother tongue/native language in one's English language speech production. International Journal of English and Education, 3(3). Retrieved from www.ijee.org.

Amiri, F., Jahedi, M., \& Othman, M. (2017). A case study of the development of an ESL learner's speaking skills through instructional debate. International Journal of Humanities and Social Science, 7(March), 120-126.

Bahadorfar, M., \& Omidvar, R. (2014). Technology in teaching speaking skill. Acme International Journal of Multidisciplinary Research, 2(4), 913. Retrieved from http://www.aijmr.net.

Bodana, R. (2017). Orai - Improve public speaking app for android, iOS download review \& troubleshooting.

Chang, M. (2017). Interview with Danish Dhamani, co-founder of Orai - AI Artisan. Retrieved from https://aiartisan.wordpress.com/2017/11/27/inte rview-with-danish-dhamani-co-founder-of-orai/

Daniel, M. J. (2014). Language teaching in the digital age. International Journal of Innovative Research in Science, Engineering and Technology, 3(4), 11029-11031. Retrieved from www.ijirset.com.

Doqaruni, V. R. (2014). A quantitative action research on promoting confidence in a foreign language classroom: Implications for second language teachers quantitative action research on promoting confidence in a foreign language classroom. Inquiry in Education, 5(1). Retrieved from http://digitalcommons.nl.edu/ie/vol5/iss1/3.

Douglas, L. (2017). Want to captivate an audience like Obama? There's an app for that.

Godwin-jones, R. (2009). Emerging technologies speech tools and technologies. Language Learning \& Technology, 13(3), 4-11. Retrieved from http://lit.msu.edu/vol13num3/emerging.pdf\%0A October.

Hadijah, S. (2014). Investing the problems of English speaking of Islamic boarding school program at STAIN Samarinda. Dinamika Ilmu: Jurnal Pendidikan, 14(2), 240-247. Retrieved from http://journal.iain-

samarinda.ac.id/index.php/dinamika_ilmu/articl e/view/16/pdf_17\%0Ahttps://docs.google.com/ viewerng/viewer?url=http://journal.iainsamarinda.ac.id/index.php/dinamika_ilmu/articl e/viewFile/16/pdf_17.

Leong, L. M., \& Ahmadi, S. M. (2017). An analysis of factors influencing learners' English speaking skill. International Journal of Research in English Education, 2(1), 34-41. doi: 10.18869/acadpub.ijree.2.1.34.

Muhammad, R. (2017). The importance of teaching reading: Emphasize for reading fluency or accuracy in improving students' reading comprehension in EFL context. Ethical Lingua, 3448, 127-138.

Olivia, R. (2018). 15 Tools to help students improve. Retrieved from https://www.bookwidgets.com/blog/2018/09/15 -tools-to-help-students-improve-their-publicspeaking-skills-in-the-classroom.

Srivastava, S. R. (2014). Accuracy Vs fluency in English classroom. New Man International Journal of Multidisciplinary Studies, 1(4), 2348-1390. Retrieved from www.newmanpublication.com.

Takahashi, D. (2017). Orai app uses AI to help you become a better public speaker.

Wang, Z. (2014). Developing accuracy and fluency in spoken English of Chinese EFL learners, 7(2), 110-118. doi: 10.5539/elt.v7n2p110.

Yang, Y. I. J. (2014). Is speaking fluency strand necessary for the college students to develop in the EFL class? Theory and Practice in Language Studies, 4(2), 225-231. doi: 10.4304/tpls.4.2.225-231. 